\title{
BALANCE DE MUERTES Violentas \\ OCURRIDAS EN El CONTEXTO DE LA \\ Conflictividad Política En Venezuela \\ Durante Abril-Julio DE 2017
}

\section{Keymer Ávila ${ }^{1}$ Natalia Gan ${ }^{2}$}

Resumen: El presente artículo tiene como objetivo realizar un balance general sobre las muertes ocurridas durante la conflictividad política en Venezuela entre abril y julio de 2017. Se comienza con un análisis del contexto político y social, en el cual se refleja la crisis institucional que generó la ola de protestas. A continuación se ofrece una serie de consideraciones conceptuales sobre el uso excesivo de la fuerza, dando cuenta sobre la obligación que tienen los funcionarios de seguridad de asegurar el derecho a la vida y a la manifestación pacífica, razones por las cuales deben utilizar la fuerza de manera legal y proporcional. Luego, se explica la base normativa nacional sobre control de manifestaciones, donde se especifican los principios que los funcionarios deben respetar. Además, se expone la distribución de competencias entre los distintos cuerpos de seguridad venezolanos en

\footnotetext{
${ }^{1}$ Abogado Magna cum Laude, egresado de la Universidad Central de Venezuela (UCV). Máster Oficial en Criminología y Sociología Jurídico Penal, Universitat de Barcelona (UB). Investigador del Instituto de Ciencias Penales de la UCV. Profesor de Criminología en pre y postgrado de la misma universidad. Colaborador del Observatorio del Sistema Penal y los Derechos Humanos de la UB. Miembro de la Asociación Latinoamericana de Derecho Penal y Criminología (ALPEC). Correo electrónico: keymerguaicaipuro@gmail.com

${ }^{2}$ Licenciada de Estudios Liberales Summa cum Laude, egresada de la Universidad Metropolitana (Unimet). Máster de Artes en Relaciones Internacionales, Hult International Business School, Londres, Reino Unido. Profesora de Teorías de Relaciones Internacionales en la Universidad Metropolitana. Correo electrónico: gan.natalia@gmail.com
} 
cuanto a control de manifestaciones. Se continúa con la presentación de una caracterización de las muertes ocurridas entre el 6 de abril y el 27 de julio con base en los registros publicados por el Ministerio Público, incluyendo en el análisis las variables de lugar, fecha, tipo de medio empleado, así como perfiles de víctimas y de victimarios. Por último, se ofrecen unas reflexiones finales con miras a establecer algunas recomendaciones ante el difícil contexto que se vislumbra en el futuro inmediato.

Palabras claves: derecho a la manifestación pacífica; derecho a la vida; control de manifestaciones; uso excesivo de la fuerza; servicio de policía; Venezuela.

Abstract: This article has the objective of taking stock of the deaths occurred during the political unrest in Venezuela between April and July 2017. It begins with an analysis of the political and social context, reflecting the institutional crisis that led to the protests. Then, a series of conceptual considerations about the excessive use of force are offered in order to give an account of the obligation of security officials to guarantee and assure the right to life and to pacific assembly, as well as the obligation to use the force legally and proportionally. The national laws on the police management of mass demonstrations and the distribution of competences among the different security corps are stressed next. It continues with a characterization of the deaths occurred between April 6 and July 27 based on the reports published by the State Attorney's General Office, including variables such as place and date of deaths, as well as profiles of victims and perpetrators. Lastly, some final conclusions are presented in order to offer recommendations ahead of the complicated context that 2018 brings.

Keywords: right to protest; right to pacific assembly; right to life; police management of demonstrations; excessive use of force; police service; Venezuela 
Resum: El present article té com a objectiu fer un balanç general de les morts ocorregudes durant la conflictivitat política a Veneçuela entre abril i juliol de 2017. S’hi comença amb una anàlisi del context polític i social, en la qual es reflecteix la crisi institucional que va generar l'onada de protestes. Tot seguit, s'hi ofereix una sèrie de consideracions conceptuals sobre l'ús excessiu de la força, tal vegada que s'hi exposa l'obligació que tenen els funcionaris de seguritat d'assegurar el dret a la vida $i$ a la manifestació pacífica, raons per les quals han d'utilitzar la força de manera legal i proporcional. Després, s'hi explica la base normativa nacional sobre control de manifestacions, on s'especifiquen els principis que els funcionaris han de respectar. A més, s'hi exposa la distribució de competències entre els diferents cossos de seguretat veneçolans pel que fa al control de manifestacions. L'article prossegueix amb la presentació d'una caracterització de les morts ocorregudes entre el 6 d'abril i el 27 de juliol basada en els registres publicats pel Ministeri Públic, incloent a l'anàlisi variables de lloc, data, tipus de mitjà emprat, així com perfils de víctimes i victimaris. Per acabar, s'hi ofereixen unes reflexions finals a fi d'establir algunes recomanacions davant del difícil context que s'entreveu en un futur immediat.

Paraules clau: dret a la manifestació pacífica; dret a la vida; control de manifestacions; ús excessiu de la força; servei de policia; Veneçuela

\section{Introducción}


El presente artículo tiene como objetivo hacer un balance general sobre las muertes ocurridas en el contexto de la conflictividad política acaecida entre los meses de abril y julio de 2017. La fuente principal de este análisis son los registros publicados por el Ministerio Público hasta el 5 de agosto de 2017. Es de advertir que la mayoría de estos casos se encuentran aún en fase de investigación, y que a partir de esa fecha se ha dejado de informar oficialmente sobre los mismos, razón por la cual esta información no es definitiva ni concluyente. Por ello, este trabajo será solo una primera aproximación a estos eventos. Estos datos fueron complementados con el seguimiento diario de noticias desde que se inició esta coyuntura hasta finales del año 2017. Se considera importante ir documentando todo lo que ha venido sucediendo durante estos años, no solo como ejercicio académico de sistematización, se trata también de hacer un aporte para la construcción colectiva de la memoria, esta última tarea es fundamental en estos tiempos.

1. Contexto: el caldo de cultivo de las protestas iniciadas el 6 de abril de $2017^{3}$

Venezuela, país que forma parte de diversos intereses geoestratégicos de potencias como EEUU, Rusia y China, durante los últimos años ha estado inmersa en una crisis progresiva de diversas índoles: económica, política e institucional. Crisis que se ha agudizado con la inflación y escasez general de productos, en especial de alimentos y medicinas; una tasa de homicidios de 70,1 por cada cien mil habitantes (Ministerio Público, 2017a) alimentada en parte por operativos policiales cuestionados por su violación en materia de derechos humanos como las denominadas Operaciones de Liberación del Pueblo (OLP); poca claridad y cohesión en los liderazgos políticos, en especial a partir de la muerte

\footnotetext{
${ }^{3}$ Esta sección tiene como base artículos y posiciones que se hicieron públicas durante la coyuntura objeto de análisis (Ávila, 2017a; Carcione, 2017).
} 
del Presidente Chávez en el año 2013, lo que ha traído como consecuencia una disminución de la hegemonía del partido de gobierno, cuya expresión más evidente está en la derrota electoral del 6 de diciembre de 2015, en la que, después de 18 años, la oposición retoma el dominio del Poder Legislativo (Ávila, 2017b). Antes del triunfo electoral de la oposición, la Asamblea Nacional (AN) saliente designó a nuevos Magistrados en el Tribunal Supremo de Justicia (TSJ) a través de un procedimiento que ha sido cuestionado tanto en su forma como en su fondo (Hernández 2017a; 2015a; 2015b; Acceso a la Justicia, 2015a; 2015b; Academia de Ciencias Políticas y Sociales, 2015; El Nacional, 2015; Contrapunto, 2017). Estos últimos dos eventos trajeron consigo una serie de acciones institucionales de desconocimientos recíprocos, a continuación se señalarán las que se consideran más relevantes (Terán, 2017; Falak, 2017):

1. Los magistrados designados a través del cuestionado procedimiento, entre finales de diciembre de 2015 y comienzos de enero de 2016, decidieron desincorporar a los diputados electos en diciembre por el estado Amazonas, lo que afectó a la mayoría calificada de la oposición en la AN (Hernández 2016). Decisión que la AN acató días después (Embajada de la República Bolivariana de Venezuela en Cuba, 2016). A la fecha de elaboración de este trabajo, luego de casi tres años, aún no se ha decidido sobre ese caso, cuando lo que procedía en el supuesto más extremo era la celebración inmediata de nuevas elecciones.

2. Siete meses después, el 28 de julio de 2016, alegando que el TSJ no decidía sobre el caso de los diputados de Amazonas, la AN incorporó a dichos diputados, lo que el TSJ respondió invalidando todas las decisiones de la misma, porque se encontraría en desacato (El Universal, 2016b; El Nacional, 2016).

3. Cuando la AN decidió obedecer y separar nuevamente a los diputados de Amazonas, el TSJ desconoció este acto parlamentario, alegando cuestiones de forma. Al año siguiente, en 
enero de 2017, con nueva junta directiva, la AN obedece nuevamente la orden del TSJ, sin embargo, éste vuelve a anular la decisión, alegando esta vez que la sesión debía realizarse bajo el mandato de la junta directiva anterior, la que se encontraba en funciones antes de la primera declaración de desacato (Falak, 2017; Crespo, 2017).

4. El 13 de diciembre de 2016 la AN aprobó la responsabilidad política del Presidente de la República "por la grave ruptura del orden constitucional y democrático, la violación de derechos humanos y la devastación de las bases económicas y sociales de la nación”. Semanas después, el 9 enero de 2017, declaran el "abandono del cargo" del Presidente, medidas de cuestionada constitucionalidad y legalidad que forman parte de los continuos desconocimientos entre el Poder Ejecutivo y Legislativo que se agudizarán en las semanas siguientes (Peñaloza, 2017; Telesur, 2017b; Hernández 2017e; León, 2016).

5. El Poder Ejecutivo negocia acuerdos comerciales que comprometen la biodiversidad de casi el 12\% del territorio nacional, colocando la explotación minera en manos de industrias militares y extranjeras (Cano, 2016; Otero, 2016).

6. El Poder Electoral hizo prácticamente inviable el referendo revocatorio presidencial (BBC, 2016a; Alba Ciudad, 2016;) y postergó sin fecha las elecciones de gobernadores que correspondían en diciembre de 2016. Mientras tanto las autoridades regionales ejercieron de facto sus funciones (Falak, 2017; BBC, 2016b; El Universal, 2016a). El Ejecutivo llegó a designar administrativa y discrecionalmente a algunos gobernadores, sin que mediaran procesos electorales para ello, como en los casos de: Carabobo (Analítica, 2017), Barinas (Camacho, 2017), Sucre (León 2017b) y Anzoátegui (Agencia Venezolana de Noticias, 2016).

7. Se promulgaron las sentencias 155 (Tribunal Supremo de Justicia, 2017a; Hernández, 2017d) y 156 (Tribunal Supremo de Justicia, 2017b; Hernández, 2017c), del 27 y 29 de marzo de 2017, en 
las que se desconoce a la AN y le otorgan al Ejecutivo parte de sus competencias, las cuales fueron cuestionadas por diversos sectores del país (Reyes, 2017; Ávila, 2017h). El 31 de marzo la Fiscal General, en el marco de la presentación de su informe anual, rechazó públicamente la constitucionalidad de dichas sentencias, señalando que constituían una "ruptura del orden constitucional" (Ortega, 2017a). Días después impugnó el nombramiento de los Magistrados realizado a finales de 2015 (El Nacional, 2017a), lo que generó una serie de ataques y acciones en su contra y del Ministerio Público, de parte del Ejecutivo Nacional, el Defensor del Pueblo, el Contralor General de la República y el TSJ (Hernández, 2017b; Ávila, 2017e; 2017d) que tendría su máxima expresión en su polémica e irregular destitución por parte de la Asamblea Nacional Constituyente el 5 de agosto de 2017.

8. Ante el inicio del procedimiento por parte del Ejecutivo Nacional para retirar al país de la OEA (Ladera, 2017), el desconocimiento mutuo entre el Poder Ejecutivo, Judicial y Legislativo, y la imposibilidad de resolver institucionalmente las controversias, se iniciaron una serie de protestas y manifestaciones entre el 4 y el 6 de abril de 2017, cuyo objetivo inicial era procurar la destitución de los magistrados del TSJ (Pineda 2017; El Nacional 2017d; 2017e; 2017b; 2017c), los objetivos, formas y características de las protestas fueron diversas.

9. A casi un mes después de las protestas, el 1 de mayo, el Presidente convocó a una Asamblea Nacional Constituyente, que fue cuestionada en su constitucionalidad, legitimidad, pertinencia y objetivos (Panorama, 2017; León 2017a; El Universal, 2017; Ávila, 2017g).

10. Luego del anuncio presidencial sobre la posibilidad de ir a un proceso constituyente las protestas continuaron, junto a la represión a las mismas, así como el desconocimiento entre diversas instituciones del Poder Público Nacional. Esta situación duró aproximadamente hasta los primeros días de agosto cuando el 
gobierno logra imponer, luego de un dudoso y cuestionado proceso electoral (Observatorio Electoral Venezolano, 2017a; 2017b; 2017c), la Asamblea Nacional Constituyente (Telesur, 2017a).

Es este el contexto en el que se realizará el presente análisis sobre el uso excesivo de la fuerza durante la conflictividad ocurrida en Venezuela entre los meses de abril y julio de 2017, en especial la vinculada al control de manifestaciones.

\section{Uso excesivo de la fuerza}

Amnistía Internacional utiliza el término "Uso de la Fuerza" solo en situaciones de aplicación de la ley, lo que abarca supuestos como detenciones, prevención del delito y control de manifestaciones (Amnistía Internacional, 2015a).

Las fuerzas de seguridad o agentes del orden son todos aquellos que cumplen labores de policía, sean estos civiles o militares, quienes deben regirse en el ejercicio de sus funciones por el Código de conducta para funcionarios encargados de hacer cumplir la ley (Asamblea General de la ONU, 1979), así como por los Principios básicos sobre el empleo de la fuerza $y$ de armas de fuego por los funcionarios encargados de hacer cumplir la ley (Oficina del Alto Comisionado para los Derechos Humanos, 1990) (en adelante principios básicos). Razón por la cual los gobiernos deben asegurar que los agentes encargados de la ley usen la fuerza solo cuando sea estrictamente necesaria, la cual debe ser aplicada de manera legal y proporcional, con la debida rendición de cuentas posterior. En virtud de estos principios, las fuerzas de seguridad deben tomar medidas para minimizar el riesgo de lesiones y muerte. Es por ello que la fuerza letal y las armas de fuego no deben utilizarse excepto cuando sea estrictamente necesario para proteger otra vida (principio básico 9). En estos casos, los hechos deben ser investigados de manera inmediata, exhaustiva, independiente e imparcial por los organismos correspondientes (principios básicos 6, 11 y 22). 
En línea con los principios básicos (12-14), los gobiernos y las agencias de la ley deben reconocer el derecho a participar en manifestaciones y reuniones lícitas y pacíficas establecidos en la Declaración Universal de Derechos Humanos (artículo 20.1), el Pacto Internacional de Derechos Civiles y Políticos (artículo 12), y en el contexto venezolano en su propia Constitución (CRBV) (artículos 68 y 53). El uso de la fuerza en la dispersión de reuniones públicas no violentas debe ser evitado.

Venezuela, además, cuenta con instrumentos constitucionales, legales y reglamentarios que desarrollan las normativas mencionadas, y en algunos casos son más progresivos que los instrumentos internacionales. Por ejemplo, establece el carácter civil de este tipo de labores, el Uso Progresivo y Diferenciado y de la Fuerza Policial (UPDFP), así como la prohibición del uso de armas de fuego para el control de manifestaciones pacíficas. Estas normas nacionales serán descritas a continuación.

\section{Base normativa nacional sobre el control de manifestaciones ${ }^{4}$}

Según el Manual de actuación de los cuerpos de policía para garantizar el orden público, la paz social y la convivencia ciudadana en reuniones públicas y manifestaciones -MACPGOP- (Consejo General de Policía, 2012) -basado en la resolución ministerial que rige esta materia (Normas sobre la actuación de los cuerpos de policía en sus diversos ámbitos político territoriales para garantizar el orden público, la paz social y la convivencia ciudadana en reuniones públicas y manifestaciones -NACPOP_ del año 2011), el control de manifestaciones es "el servicio policial orientado al resguardo de los derechos humanos y garantías de las personas que participan en reuniones públicas y manifestaciones, con el objeto de asegurar la paz social, la convivencia

\footnotetext{
${ }^{4}$ Para toda esta sección se tomó como base: Ávila, 2015: 504-511.
} 
ciudadana y el respeto de la legalidad, teniendo como premisa fundamental la mediación o negociación de los conflictos por vías pacíficas".

Los diversos instrumentos legales venezolanos que rigen la actuación de los cuerpos de seguridad encargados del control de manifestaciones establecen normas que deben respetarse, a fin de garantizar el equilibro armónico entre la protección de los derechos humanos de los manifestantes y el aseguramiento de los derechos de los funcionarios policiales (art. 2 NACPOP; art. 8 Ley del Estatuto de la Función Policial -LEFP_). Destacan así las siguientes:

1. Priorizar el respeto y garantía del derecho bumano a la vida como valor supremo en un Estado Democrático y Social, de Derecho y de Justicia (arts. 43 y 2 CRBV; 5.1. NACPOP).

2. Velar por el disfrute del derecho a reunión y del derecho a manifestar pacificamente y sin armas (art. 68 CRBV; art.65.6 Ley Orgánica del Servicio de Policía y Cuerpo de Policía Nacional Bolivariana -LOSPCPNB-; arts.9.6 у 21 NACPOP).

3. Ponderar derechos humanos: los funcionarios deben ponderar las posibles amenazas o violaciones a los derechos humanos y garantías cuando existan conflictos en el disfrute y ejercicio de los derechos de quienes participan en manifestaciones frente a los derechos de las demás personas. Deben considerar la existencia de alternativas para su disfrute o ejercicio simultáneo, observando en todo momento la protección especial a la vida, la salud e integridad personal (artículos 8 de la LEFP y 5.2 de las NACPOP).

4. Dar una respuesta oportuna, necesaria e inmediata para proteger a las personas y a las comunidades, frente a situaciones que constituyan amenaza, vulnerabilidad, riesgo o daño para su integridad física, su hábitat y sus propiedades (art.8 LOSPCPNB).

5. Proteger especialmente a las poblaciones en situación de vulnerabilidad, niños o adolescentes, así como adultos mayores y las personas con discapacidad (arts. 65.9 LOSPCPNB; 5.3, 21.1 NACPOP). 
6. Utilizar siempre el uso de medios alternativos de solución de conflictos (diálogo, negociación, mediación, entre otros) como primera medida de actuación (arts. 4.5 LOSPCPNB; 5.5, 9.7 NACPOP). La participación del negociador tiene como finalidad disuadir las expresiones de violencia por parte de los manifestantes y que se evite la medida de la fuerza. Todos los cuerpos de policía deberán contar con un equipo de negociadores capacitados para adelantar labores de conciliación y mediación.

7. Utilizar la fuerza solo cuando todos los medios de negociación y persuasión se bayan agotado. Antes de hacer uso de la fuerza los oficiales deberán advertir verbalmente e intentar persuadir a las personas manifestantes (art. 21 NACPOP) a través del diálogo o empleando equipos altoparlantes (arts. 19 y 20 NACPOP).

8. Hacer el menor uso de la fuerza policial posible para garantizar su integridad fisica y sus derechos o los de terceros, siguiendo los principios de legalidad, necesidad y proporcionalidad. Esta tarea requiere de entrenamiento, equipamiento adecuado y mucha preparación física y psicológica (art. 5, numerales 4 y 6 ; arts. 13, 14, 17.2 y 30 NACPOP). La LOSPCPNB en sus artículos 68 al 71 consagran los principios del UPDF que deben ser aplicados por los cuerpos policiales. En las páginas 34 a la 37 del MACPGOP se presenta una escala del conflicto referencial para el uso de la fuerza policial durante el control de reuniones públicas y manifestaciones. No se debe utilizar la fuerza contra las personas que huyen o caen mientras corren, salvo la estricta necesaria en caso de flagrancia en la comisión de un delito (art. 21.2 NACPOP).

9. Utilizar armamento de carácter defensivo no letal, por ejemplo, bastones policiales, gas lacrimógeno, cañones de agua, granadas de distracción, lanzadores de municiones no letales, etc. Además del traje antitrauma (compuesto por casco antimotín con protección de cuello y recubrimiento interior, chaleco balístico, protectores de pectorales, brazos, genitales, muslos, cadera, coxis, rodillas, tibia, peroné, tobillos y empeine), escudo antimotín, máscara antigás, extintor de fuego, megáfono, vallas separadoras y esposas de acero. Toda Dirección de Control de Reuniones Públicas y Manifestaciones debe contar con unidades de transporte policial de orden público, con cabina trasera y 
salida lateral, así como con una unidad de transporte blindada de la misma naturaleza, con bomba y rociador de agua.

9.1. No se debe propulsar agentes químicos en forma directa contra las personas. Se deben tomar precauciones en el uso de agentes químicos, a fin de evitar su difusión y extensión en inmediaciones o cercanía de edificaciones que congreguen personas con mayor riesgo de sufrir sus consecuencias, tales como hospitales, geriátricos, escuelas, liceos y colegios, así como espacios confinados o sitios cerrados (art. 21.3 NACPOP).

9.2. Cuidar que el empleo de carabinas y escopetas para el lanzamiento de los agentes químicos y el gas se efectúe por personal debidamente capacitado y entrenado para tal fin, de conformidad con las directivas vigentes.

10. Reconocer "que las personas en una multitud son individuos, no una mera muchedumbre sin rostro (...). Dichos funcionarios deben asegurarse de que las acciones puntuales se dirijan sólo contra los individuos que infrinjan la ley y no afecten a los testigos inocentes, quienes deberían poder continuar manifestándose sin interrupciones" (Comité Internacional de la Cruz Roja, 2008).

12. Abstenerse de usar armas de fuego en el control de manifestaciones pacíficas (arts.68 CRBV; 21.9 NACPOP). En consecuencia, el arma de fuego solo debe usarse en circunstancias extremas, como reacción al ejercicio de una fuerza letal para la defensa de la propia persona o de terceros, ante una agresión ilegítima, únicamente en contra de quien o quienes representen tal nivel de amenaza, atendiendo siempre a los principios de necesidad, oportunidad y proporcionalidad. Es importante destacar que los principios básicos tienen en cuenta el carácter frecuentemente peligroso de la labor policial, señalando "que la amenaza de la vida y la seguridad de los funcionarios encargados de hacer cumplir la ley debe considerarse como una amenaza a la estabilidad de toda la sociedad".

14. Tener siempre en cuenta el Código de conducta para funcionarios encargados de hacer cumplir la ley (CCFEHCL) que contiene directrices éticas y legales transversales para su profesión. 
15. El coordinador de reuniones públicas y manifestaciones en cuanto reciba la información sobre la manifestación debe obtener información precisa acerca de la situación y hacer los estudios, análisis, planificación táctica y estratégica, y demás preparativos correspondientes. Una vez finalizada la actividad, conjuntamente con el personal supervisor, evaluará la actuación de las unidades durante la situación atendida, identificarán las posibles fallas $e$ implementarán los correctivos que sean necesarios (arts. 10, 17, 19, 20, 21 у 22 NACPOP).

\section{Distribución de competencias entre los distintos cuerpos de seguridad en el control de manifestaciones}

En esta materia pueden distinguirse claramente cuatro niveles de intervención que van de una situación de complejidad menor a una mayor, a la que corresponde a su vez niveles de intervención policial equivalentes, basados en los niveles y criterios de actuación policial establecidos en los artículos 50 al 54 de la LOSPCPNB en concordancia con los artículos 8, 9 y 10 de la Ley de Coordinación de Seguridad Ciudadana (LCSC) y 9.9 de las NACPOP, éstos son los siguientes:

1. Policías Municipales: si bien no tienen competencia directa en el control de manifestaciones, ni cuentan con los equipos para estas tareas, los cuerpos de policía municipales deben circunscribir el ejercicio de sus actividades, de conformidad con lo previsto en los artículos 44 (naturaleza de los cuerpos de policía municipal) y 50 (criterios y niveles de actuación policial) de la LOSPCPNB, contribuyendo con las orientaciones debidas a las personas y el control del perímetro externo de la zona de conflicto, a fin de preservar la seguridad de las mismas, prevenir y evitar la escalada en la confrontación y facilitar la operatividad de los demás cuerpos policiales (art. 4 NACPOP).

2. Policías Estadales: tienen la facultad de organizar personal entrenado y equipado para el control de reuniones y manifestaciones que comprometan el orden público, la paz social y la convivencia, en su espacio territorial (art. 43 LOSPCPNB). Las policías Estadales son 
las responsables directas de contener las manifestaciones y asegurar el orden público en su territorio. En caso de que ésta se vea superada en su capacidad y medios, debe ser apoyada de inmediato por los cuerpos nacionales existentes con competencia en esta materia la PNB o la GNB.

3. Policía Nacional Bolivariana (PNB): Tiene competencia en todo el territorio nacional en materia de orden público (art. 37 LOSPCPNB) interviene cuando la intensidad de la situación rebasa la capacidad y medios de las policías estadales.

4. Guardia Nacional Bolivariana (GNB): desde el deber ser, en esta etapa transitoria de desarrollo y fortalecimiento institucional de la PNB, la GNB ejerce también de manera subsidiaria labores de control de manifestaciones y de orden público, este apoyo en la prestación de esta área del servicio de policía la deben ejercer solo cuando los cuerpos policiales anteriores se vean rebasados en su capacidad y medios. En estos casos la GNB debe regirse también por las normas descritas (arts.1, 5.4 NACPOP; 27 LCSC; 65 numerales 2 y 6 de la Ley Orgánica de la Fuerza Armada Nacional Bolivariana -LOFANB-; comentario al artículo 1 del CCFEHCL) y estar a las órdenes de la autoridad civil (65.2 LOFANB; 22.7 LOSPCPNB; 27 LCSC).

\section{Caracterización de los casos ocurridos entre el 6 de abril y el 27 de julio $^{5}$}

Basado en los registros publicados por el Ministerio Público sobre la conflictividad iniciada a partir del 6 de abril, sistematizada por esta

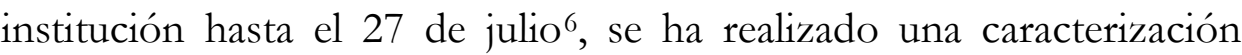
inicial de la violencia mortal, así como de las víctimas de la misma,

\footnotetext{
${ }^{5}$ Se toman como antecedentes de esta totalización los adelantos parciales realizados en plena coyuntura, en especial: Ávila, 2017f; 2017b.

${ }^{6}$ Es importante destacar que con posterioridad al 27 de julio se registraron otras muertes, por ejemplo, el mismo día de las elecciones de la Asamblea Nacional Constituyente (30 de julio) el propio Ministerio Público informó de 10 muertes. Otras fuentes como el Observatorio Venezolano de Conflictividad Social (2017) señala 163 muertes hasta el 13 de agosto.
} 
durante los cuatro meses de conflicto. El último informe del Ministerio Público totaliza para esa fecha 109 personas fallecidas ${ }^{7}$. Como se señaló al inicio, todos estos casos se encuentran en fase de investigación, razón por la cual esta información no es definitiva ni concluyente. El promedio es prácticamente de un fallecido por cada día de conflicto (109 víctimas en 112 días). Desde lo situacional puede afirmarse que es una violencia que ocurre en el espacio público y que tiene como principal instrumento las armas de fuego (71\%), la mayoría de las muertes han ocurrido en el contexto de manifestaciones (84\%). En al menos un $21 \%$ de estos casos hay responsabilidad de las fuerzas de seguridad del Estado ${ }^{8}$, en un porcentaje aún mayor se puede evidenciar el ataque de civiles armados contra los manifestantes $\left(24 \%{ }^{9}\right)$.

El cuerpo de seguridad vinculado a la mayor cantidad de casos es la GNB (52\%), seguida de las policías estadales $(17 \%)$ y las municipales (13\%). En los primeros dos casos es de esperarse ya que son cuerpos con competencia en materia de control de manifestaciones, en este sentido llama la atención que las policías municipales, que no tienen estas competencias, tengan más casos que la PNB (9\%) que sí las tienen.

El total de funcionarios fallecidos es de 7 , lo que representa el $6,4 \%$ de las víctimas totales, y que constituye un indicador de que no

7 Ministerio Público, Balance de víctimas fallecidas y lesionadas durante manifestaciones desde el 6 abril al 27 de julio de 2017 (Ministerio Público, 2017b). Disponible originalmente en la página web del Ministerio Público hasta el 5-8-2017 fecha del asalto militar a esta institución por órdenes de la Asamblea Nacional Constituyente, lo que trajo como consecuencia, entre otras, la supresión de toda la información que había colgado la gestión anterior sobre sus acciones vinculadas con estos casos.

${ }^{8}$ La Fiscal General después del 5 de agosto ha afirmado que este número es más elevado: 25\% (Ortega, 2017b).

${ }^{9}$ Posteriormente, la Fiscal General afirmaría que ese porcentaje alcanzaría un 40\%, sin embargo, no presentan información detallada al respecto, este dato lo ofrece como parte de un comunicado más extenso en el que aborda el ataque que sufrió el Ministerio Público durante esos días: Ortega, ídem. 
todas las manifestaciones fueron pacíficas; por el contrario, en algunos casos se tornaron violentas e incluso delictivas. Por ejemplo, pudieron contarse 13 personas fallecidas en intentos de saqueo, representando éstas un $12 \%$ de las muertes totales.

La violencia de algunas manifestaciones también puede apreciarse en el número de lesionados que supera las 1.934 personas, 61\% como consecuencia de la intervención de las fuerzas de seguridad del Estado.

Llama la atención como la obstaculización de vías también ha generado situaciones de conflictividad que han ocasionado 13 muertes por arrollamientos y accidentes de tránsito, lo que se ubica como la segunda causa de las muertes analizadas (12\% de la conflictividad en general y $14,4 \%$ de las ocurridas en el marco de las manifestaciones).

Por uso indebido de bombas lacrimógenas murieron 4 personas, ya sea por impacto directo (2) o por asfixia (2). Tres personas han fallecido por explosivos y 2 personas han sido linchadas y quemadas.

En cuanto al perfil de las víctimas el 93\% son hombres, su edad promedio es de unos 27 años. El 34\% pertenece a la clase trabajadora y un $27 \%$ son estudiantes, estos dos sectores constituyen el perfil mayoritario de las víctimas (61\%).

Los estados con mayor cantidad de víctimas son el Distrito Capital (24\%), Lara (15\%), Carabobo (9\%), Miranda (9\%), Zulia (9\%), Barinas (8\%), Mérida (8\%) y Táchira (7\%). Estos ocho estados suman el $90 \%$ de las víctimas fatales.

En cuanto a la respuesta institucional, en el 91\% de los casos en los que se especifica en el informe del MP que están involucrados funcionarios se tiene la identificación del organismo responsable. En el 48\% de los casos los funcionarios involucrados están identificados e imputados, sumando un total de 34 funcionarios, de éstos 31 fueron privados de libertad, esto significa que en un 35\% de estos casos se privó de libertad a los presuntos responsables. Solo en 2 casos $(9 \%)$ los funcionarios habían sido acusados. 
Esto contrasta con los casos en los que los victimarios son civiles armados, de 26 casos, solo en 7 (27\%) hay victimarios identificados, en 5 hay privados de libertad, y en apenas 1 hay un acusado.

1. Total de fallecidos: 109 personas en 112 días, prácticamente una persona fallecida por día.

\begin{tabular}{|c|c|c|}
\hline $\begin{array}{l}\text { Fallecidos totales en el marco de la } \\
\text { conflictividad }\end{array}$ & 109 & $100 \%$ \\
\hline $\begin{array}{l}\text { Total de fallecidos por arma de fuego en el } \\
\text { marco de la conflictividad general }\end{array}$ & 77 & $70,6 \%$ \\
\hline $\begin{array}{l}\text { Arrollamientos o accidentes de tránsito } \\
\text { producto de la obstaculización de vías }\end{array}$ & 13 & $12 \%$ \\
\hline Electrocutados en intento de saqueo & 9 & $8 \%$ \\
\hline Uso indebido de bombas lacrimógenas & $4^{10}$ & $3,7 \%$ \\
\hline Por explosivos & 3 & $2,8 \%$ \\
\hline Linchamiento, armas blancas y uso de fuego & 2 & $1,8 \%$ \\
\hline Objeto contundente & 1 & $0,9 \%$ \\
\hline Total & 109 & $100 \%$ \\
\hline
\end{tabular}

- Fallecidos en el contexto de manifestaciones: 92 (84\% de las muertes totales en el marco de la conflictividad)

\begin{tabular}{|l|r|r|}
\hline $\begin{array}{l}\text { Fallecidos en el contexto de } \\
\text { manifestaciones }\end{array}$ & $\mathbf{9 2}$ & $100 \%$ \\
\hline $\begin{array}{l}\text { Fallecidos en manifestaciones por arma de } \\
\text { fuego }\end{array}$ & 72 & $78 \%$ \\
\hline $\begin{array}{l}\text { Arrollamientos o accidentes de tránsito } \\
\text { producto de la obstaculización de vías }\end{array}$ & 13 & $14 \%$ \\
\hline
\end{tabular}

${ }^{10} 2$ por asfixia y 2 por impacto directo. 


\begin{tabular}{|l|r|c|}
\hline Uso indebido de bombas lacrimógenas & $3^{11}$ & $3 \%$ \\
\hline Por explosivos & 2 & $2 \%$ \\
\hline Linchamiento, armas blancas y uso de fuego & 2 & $2 \%$ \\
\hline & 92 & $100 \%$ \\
\hline
\end{tabular}

- Muertes provocadas por la intervención directa de las fuerzas de seguridad del Estado en el contexto de manifestaciones: $23(26 \%$ del total de las muertes en manifestaciones y el $21 \%$ de las muertes generales de la conflictividad ocurrida entre abril y julio de 2017).

\begin{tabular}{|l|c|c|}
\hline $\begin{array}{c}\text { Fallecidos por intervención } \\
\text { directa de cuerpos de } \\
\text { seguridad }\end{array}$ & 23 & $100 \%$ \\
\hline Guardia Nacional & $12^{12}$ & $52 \%$ \\
\hline Policía estadal & $4^{13}$ & $17 \%$ \\
\hline Policía municipal & 3 & $13 \%$ \\
\hline PNB & 2 & $9 \%$ \\
\hline Sin información & 2 & $9 \%$ \\
\hline & 23 & $100 \%$ \\
\hline
\end{tabular}

- Muertes provocadas por civiles armados en el contexto de manifestaciones: 26 (representa porcentajes mayores que las muertes por intervención de la fuerza pública: 24\%). Las fuerzas de seguridad del Estado y los grupos civiles armados son responsables de casi el 50\% de estas muertes.

\footnotetext{
111 por asfixia 2 por impacto

${ }^{12}$ En dos casos participó de manera conjunta con la policía de Lara.

132 de la policía de Carabobo, 1 de la policía de Táchira y 1 de la policía de Bolívar. Llegarían a 6 casos si se les suman los 2 casos en los que la policía del Estado Lara actuó en conjunto con la GNB, alcanzando así un $26 \%$.
} 


\section{Perfil de las víctimas}

\begin{tabular}{|c|c|c|}
\hline Sexo & $\mathbf{N}^{\circ}$ & $\mathbf{\%}$ \\
\hline Hombres & 101 & $93 \%$ \\
\hline Mujeres & 8 & $7 \%$ \\
\hline Total & 109 & $100 \%$ \\
\hline
\end{tabular}

\begin{tabular}{|c|c|c|}
\hline \multicolumn{2}{|c|}{ Edad } \\
\hline Promedio & $\begin{array}{l}27 \\
\text { años }\end{array}$ & $\%$ \\
\hline $\begin{array}{c}\text { No habían cumplido } 25 \\
\text { años }\end{array}$ & 52 & $52 \%$ \\
\hline $\begin{array}{c}\text { No habían alcanzado la } \\
\text { mayoría de edad }\end{array}$ & 13 & $12 \%$ \\
\hline
\end{tabular}

\begin{tabular}{|c|c|c|}
\hline Edades & $\mathrm{N}^{\circ}$ & $\%$ \\
\hline-18 & 13 & $11,9 \%$ \\
\hline $18-24$ & 40 & $36,6 \%$ \\
\hline $25-35$ & 34 & $31,1 \%$ \\
\hline $36-44$ & 10 & $9,1 \%$ \\
\hline $45-64$ & 12 & $11 \%$ \\
\hline Más de 64 & 0 & $0 \%$ \\
\hline Total & 109 & $100,00 \%$ \\
\hline
\end{tabular}

- Entre las víctimas se encuentran 7 funcionarios de los cuerpos de seguridad del Estado: 1 policía municipal, 3 policías estadales y 3 Guardias Nacionales, lo que representa el 6,4\% de las víctimas totales (y un $7,6 \%$ de las fallecidas en manifestaciones). Un porcentaje superior lo ocupan los comerciantes y vendedores. 


\begin{tabular}{|c|c|c|}
\hline Ocupación & $\mathrm{N}^{\circ}$ & $\%$ \\
\hline Obreros y trabajadores & 37 & $34 \%$ \\
\hline Estudiantes & 29 & $27 \%$ \\
\hline Comerciantes y vendedores & 10 & $9 \%$ \\
\hline $\begin{array}{c}\text { Funcionarios de los cuerpos de seguridad del } \\
\text { Estado }\end{array}$ & 7 & $6 \%$ \\
\hline Profesionales y técnicos & 7 & $6 \%$ \\
\hline Deportistas y músicos & 3 & $3 \%$ \\
\hline Funcionarios públicos & 2 & $2 \%$ \\
\hline Desempleados & 2 & $2 \%$ \\
\hline Discapacitados & 1 & $1 \%$ \\
\hline Sin información & 11 & $10 \%$ \\
\hline Totales & 109 & $100 \%$ \\
\hline
\end{tabular}

\section{Lesionados}

- $\quad$ Por derechos fundamentales: 1.177

- Por delitos comunes: 704

- $\quad$ Por protección integral de la familia: 53

- Totales: 1.934

\section{Víctimas de homicidio por Estados}

\begin{tabular}{|c|c|c|}
\hline Estado & $\mathbf{N}^{\circ}$ & $\mathbf{\%}$ \\
\hline Distrito Capital & 26 & $24 \%$ \\
\hline Lara & 16 & $15 \%$ \\
\hline Carabobo & 10 & $9,1 \%$ \\
\hline Miranda & 10 & $9,1 \%$ \\
\hline Zulia & 10 & $9,1 \%$ \\
\hline Barinas & 9 & $8,2 \%$ \\
\hline Mérida & 9 & $8,2 \%$ \\
\hline Táchira & 8 & $7,3 \%$ \\
\hline Aragua & 3 & $2,7 \%$ \\
\hline
\end{tabular}




\begin{tabular}{|c|r|r|}
\hline Anzoátegui & 3 & $2,7 \%$ \\
\hline Bolívar & 2 & $1,8 \%$ \\
\hline Sucre & 1 & $0,9 \%$ \\
\hline Trujillo & 1 & $0,9 \%$ \\
\hline Vargas & 1 & $0,9 \%$ \\
\hline Total & 109 & $100 \%$ \\
\hline
\end{tabular}

\section{Días con mayor cantidad de fallecidos ${ }^{14}$}

\begin{tabular}{|c|c|c|c|}
\hline Día & $\begin{array}{c}\mathbf{N}^{\circ} \text { de } \\
\text { víctimas }\end{array}$ & $\begin{array}{c}\text { \% sobre el } \\
\text { total de } \\
\text { casos }\end{array}$ & Observaciones \\
\hline $\begin{array}{c}\text { 20 de } \\
\text { abril }\end{array}$ & $\mathbf{1 3}$ & $\mathbf{1 1 , 2 \%}$ & $\begin{array}{c}\text { 8 electrocutados por } \\
\text { intento de saqueos }\end{array}$ \\
\hline $\begin{array}{c}\text { 20 de } \\
\text { julio }\end{array}$ & $\mathbf{7}$ & $\mathbf{6 , 4 \%}$ & $\begin{array}{c}1 \text { en Valencia por arma } \\
\text { de fuego, 2 en Los } \\
\text { Teques en manos de } \\
\text { funcionarios, 2 en Zulia }\end{array}$ \\
\hline
\end{tabular}

${ }^{14}$ Luego del 26 de julio (el último día incluido en el informe del Ministerio Público), hubo dos días adicionales de alta letalidad:

- $\quad$ El 27 de julio, en el cual hubo 4 víctimas: 1 por arma de fuego en Valencia durante una protesta; 1 funcionario por arma de fuego en Mérida; 1 por arma de fuego en Anzoátegui durante un saqueo; 1 en Lara durante protesta sin especificar el instrumento de muerte. La información ofrecida por el Ministerio Público fue eliminada luego del asedio militar a su sede. Dicha información fue replicada en su momento por medios de comunicación (El Carabobeño, 2017; YVKE Radio Mundial, 2017; El Cooperante, 2017, Diario de Lara La Prensa, 2017).

- $\quad$ El 30 de julio, día de la elección de la Asamblea Nacional Constituyente, en el cual el MP reportó a través de notas de prensa y tuits sobre 10 víctimas, 7 fallecidos por armas de fuego y 3 de las cuales no se informó el instrumento de muerte. 4 de las víctimas murieron en Táchira, 3 en Mérida, 1 en Sucre, 1 en Lara y 1 en Zulia. Esta publicación del Ministerio Público (2017c) actualmente no se encuentra disponible. 


\begin{tabular}{|c|c|c|c|}
\hline & & & $\begin{array}{l}\text { durante saqueos, } 1 \text { en } \\
\text { Zulia por arma de fuego } \\
\text { durante protesta y } 1 \\
\text { funcionario en Mérida } \\
\text { por arma de fuego }\end{array}$ \\
\hline $\begin{array}{l}28 \mathrm{de} \\
\text { junio }\end{array}$ & 6 & $5,5 \%$ & $\begin{array}{c}4 \text { por arrollamientos o } \\
\text { accidentes de tránsito } \\
\text { debidos a la obstrucción } \\
\text { de vías }\end{array}$ \\
\hline $\begin{array}{l}22 \mathrm{de} \\
\text { mayo }\end{array}$ & 5 & $4,5 \%$ & $\begin{array}{l}\text { Todos por arma de } \\
\text { fuego en Barinas }\end{array}$ \\
\hline $\begin{array}{l}19 \text { de } \\
\text { abril }\end{array}$ & 4 & $3,6 \%$ & 3 por armas de fuego \\
\hline $\begin{array}{l}30 \mathrm{de} \\
\text { junio }\end{array}$ & 4 & $3,6 \%$ & $\begin{array}{l}\text { Todos por arma de } \\
\text { fuego en Lara }\end{array}$ \\
\hline $\begin{array}{l}2 \mathrm{de} \\
\text { mayo }\end{array}$ & 4 & $3,6 \%$ & $\begin{array}{c}3 \text { por arrollamientos o } \\
\text { accidentes de tránsito } \\
\text { debido a la obstrucción } \\
\text { de vías }\end{array}$ \\
\hline $\begin{array}{l}26 \mathrm{de} \\
\text { julio }\end{array}$ & 4 & $3,6 \%$ & $\begin{array}{c}\text { Todos por arma de } \\
\text { fuego. } 2 \text { en Mérida y } 2 \\
\text { en Caracas }\end{array}$ \\
\hline $\begin{array}{c}\text { Total } \\
\text { es }\end{array}$ & 57 & $52,2 \%$ & \\
\hline
\end{tabular}

\section{Reflexiones finales}

A enero de 2018, todavía persiste imprecisión en cuanto a las cifras de la conflictividad política de 2017. El último informe publicado por el Ministerio Público - trabajo que sirvió de fuente para el análisis realizado- describe los perfiles de 109 víctimas y las circunstancias de sus muertes hasta el 27 de julio (Ministerio Público, 2017b). 
Posteriormente, el Ministerio Público a través de tuits y notas de prensa publicadas en su página web - que ya no se encuentran disponibles-, informó sobre la muerte de 128 personas sin dar mayor información sobre las circunstancias y presuntos responsables. En agosto de ese mismo año, la Fiscal General destituida informó que un $25 \%$ de estas muertes fueron responsabilidad directa del Estado, otro $40 \%$ fueron cometidas por civiles armados (Ortega, 2017b).

Por su parte la Oficina del Alto Comisionado de las Naciones Unidas para los Derechos Humanos (ACNUDH) (2017) reveló en su informe, que en relación a las 124 muertes registradas por el Ministerio Público hasta el 31 de julio, 46 (37\%) habían sido cometidas presuntamente por fuerzas de seguridad y 27 (22\%) por grupos armados.

Esto indica que aún no se cuenta con información exacta ni definitiva. El Ministerio Público actual, si bien ha publicado información sobre la actualización del avance de algunos casos, no ha revelado una lista definitiva de las víctimas, sus perfiles, las circunstancias y los culpables de su muerte. En este sentido, el análisis realizado en este trabajo se basó en información provisional que no refleja la totalidad de los sucesos. La publicación de esta información continúa siendo una deuda pendiente.

La ley es muy clara: los cuerpos policiales deben encargarse de garantizar el derecho a la vida, el derecho a la reunión pacífica, el derecho a la libertad y el resto del conglomerado de los derechos humanos de las personas. Para cumplir con la garantía de derechos, se han definido parámetros, reglas y normas que los funcionarios están obligados a seguir. El análisis sobre la conflictividad venezolana en el 2017 reflejó que los cuerpos de seguridad fallaron en su labor, incurriendo así en la generación de muertes de al menos 23 personas que, por el contrario, debían proteger.

La ley sugiere que los funcionarios deben abstenerse de usar armas de fuego y solo recurrir a éstas en circunstancias extremas ante 
agresiones ilegítimas que signifiquen amenazas a la vida propia o de terceros. Como se ha señalado tenemos una normativa constitucional, legal y sublegal de avanzada en esta materia (con la excepción de la polémica Resolución 8610) (Ávila, 2015). El problema en el caso venezolano no es normativo, es institucional, de controles eficaces, supervisión, fiscalización, capacitación, entrenamiento y rendición de cuentas, sin dejar de lado la grave crisis política generalizada, de legitimidad y estabilidad, que atraviesa actualmente el país.

Por otro lado, en cuanto a las armas que en principio son no letales, de acuerdo con las averiguaciones del Ministerio Público, se conoce de al menos 2 casos en los cuales funcionarios dispararon bombas lacrimógenas de forma directa contra las personas. Además, 2 personas que no estaban participando en las protestas murieron asfixiadas por los efectos de los agentes químicos disparados por funcionarios de seguridad, lo cual indica su uso indebido e indiscriminado.

El hecho de que el 61\% de las personas lesionadas (1.177 de la totalidad de 1934) lo hayan sido por funcionarios de los cuerpos de seguridad, es un indicador de la calidad de la actuación policial y militar en el control de las manifestaciones. El análisis pareciera indicar que los funcionarios fallaron en cumplir con los estándares del Uso Progresivo y Diferenciado de la Fuerza, infringiendo los principios de legalidad, proporcionalidad y necesidad.

Destaca además cómo los cuerpos de seguridad fallaron en su función de proteger a las poblaciones vulnerables, incluyendo a 13 menores de edad y un discapacitado.

Otra conclusión del análisis que evidencia el incumplimiento de la normativa, es cuando se observa que $13 \%$ de las muertes cometidas por cuerpos de seguridad hayan sido por parte de policías municipales, cuando la ley define que estas instancias no tienen competencias directas en el control de las manifestaciones. 
A su vez, alarma cómo la mayoría de las muertes cometidas por funcionarios (52\%) involucraron a la GNB, siendo ésta una instancia subsidiaria y auxiliar a la PNB en esta materia, la cual debe supeditarse a la autoridad civil. Tal dato cuestiona si realmente la GNB está respetando los protocolos de actuación correspondientes, o si por el contrario, la GNB, de estructura y operación militar, está obviando la normativa policial para imponer lógicas militares en el desempeño de sus labores policiales.

Corresponde a las autoridades venezolanas, especialmente al Ministerio de Relaciones Interiores, Justicia y Paz, garantizar que la actuación policial y militar en el control de las manifestaciones respete la normativa vigente para garantizar los derechos humanos. Es momento de superar este tipo de violaciones que no son un fenómeno nuevo. De hecho, la actuación de los cuerpos de seguridad venezolanos tradicionalmente se ha caracterizado por ser represiva y letal, no solo en el contexto de las manifestaciones, cuyo antecedente más inmediato se encuentra en las protestas del año 2014 en las cuales murieron 43 personas (Amnistía Internacional, 2015b), sino también en las prácticas policiales y militares en el marco del cumplimiento de sus funciones de seguridad ciudadana. Así, de acuerdo con la Fiscal General, 4.667 personas murieron a manos de los cuerpos de seguridad en el año 2016, representando un $22 \%$ de las víctimas totales de homicidios registradas (Manetto 2017). Ha de subrayarse además que la violencia institucional es de larga data, en la década de los 80 del siglo pasado ya había investigaciones sobre la mismas, entre ellas destacan los trabajos de Rosa Del Olmo y Tosca Hernández, en los cuales se hace una caracterización de la crisis institucional de las fuerzas de seguridad venezolanas, así como de los excesos y del carácter delictivo de las mismas (Del Olmo, 1990). Amnistía Internacional igualmente ha documentado violaciones de derechos humanos cometidas por funcionarios policiales desde los años 90 (Amnistía Internacional, 1993). 
Por su parte, el Ministerio Público tiene ahora la obligación de esclarecer todos los casos de las víctimas de la conflictividad de 2017. En primera instancia, debe cumplir con la identificación plena de los cuerpos de seguridad responsables de los homicidios. Si bien se ha identificado en el $91 \%$ de los casos a los organismos involucrados, este porcentaje se refiere a las muertes ocurridas hasta el 26 de julio. Además, si bien casi la mitad de los funcionarios implicados han sido identificados, al menos en un 52\% de los casos éstos se encuentran en libertad. Por su parte, la Fiscal General reveló en agosto de 2017 que en el $60 \%$ de los casos en los que hubo responsabilidad directa del Estado los organismos no habían ejecutado las órdenes de aprehensión de los presuntos responsables (Ortega, 2017b).

Falta esclarecer las circunstancias y responsables de la mayoría de los casos. Es así como, por ejemplo, la ACNUDH ha establecido que no ha podido precisarse información sobre la identidad de los responsables de 51 muertes (Oficina del Alto Comisionado para los Derechos Humanos, 2017). En este sentido, debe exigirse la responsabilidad inmediata tanto administrativa como penal de todos los implicados.

Se observa con gravedad cómo, según las cifras ofrecidas por el Ministerio Público de los casos ocurridos hasta el 26 de julio, grupos armados son responsables del $24 \%$ de las muertes, número que luego aumentaría a $40 \%$ de acuerdo con revelaciones de la Fiscal General en agosto. Además de implementar las medidas para que dichos grupos dejen de actuar con la aquiescencia de los cuerpos de seguridad, debe exigirse la resolución de los casos en los que están involucrados, en muchos de los cuales no queda claro el vínculo de los mismos con los funcionarios estatales. Esta indagación cobra importancia cuando en un $77 \%$ de estos casos no se ha siquiera identificado a los responsables, pudiendo esta modalidad expandirse debido al manto de impunidad que puede traer consigo. 
A medida que haya mayor transparencia y diligencia, tanto en la investigación y resolución de la totalidad de los casos, como en la publicación de la información de los mismos, mayores posibilidades habrá de que las víctimas obtengan justicia y que se garantice la no repetición de la violencia institucional y la violación a los derechos humanos de los venezolanos.

Como ya se ha afirmado, cada funcionario que se despliegue en funciones de control de manifestaciones debe reconocer y actuar conforme al principio que establece "que las personas en una multitud son individuos, no una mera muchedumbre sin rostro" (Comité Internacional de la Cruz Roja, 2008). Este principio cobra especial importancia, en un contexto donde la crisis institucional, política, social y económica se agudiza, lo que posiblemente genere nuevas olas de protestas.

En el momento de escribir estas líneas apenas acaban de transcurrir dos semanas del mes de enero y ya se cuentan más de 7 personas fallecidas en el marco de saqueos y disturbios ocurridos en 9 ciudades del país (Moreno, 2018a; Provea, 2018; El Nacional, 2018; La Patilla, 2018). Adicionalmente, fuerzas de seguridad acaban de protagonizar un operativo militarizado con resultados fatales, en los que no solamente se denuncia la participación de civiles armados actuando en conjunto con las fuerzas del Estado, además las circunstancias dejan dudas acerca de si se trató de un real enfrentamiento o de ejecuciones extrajudiciales (Efecto Cocuyo, 2018; Flores, 2018; Moreno, 2018b). La información, la caracterización de los eventos y las víctimas, la denuncia pública, la exigencia del procesamiento de los responsables, son herramientas fundamentales para evitar que este tipo de excesos se hagan cada vez más comunes en el país. Esperamos que estas líneas puedan ser de alguna utilidad en este sentido. 


\section{REFERENCIAS}

Academia de Ciencias Políticas y Sociales (10/12/2015) Pronunciamiento ante el reciente anuncio de elección de nuevos Magistrados del Tribunal Supremo de Justicia por parte de la Asamblea Nacional. Recuperado de: http://www.acienpol.org.ve/cmacienpol/Resources/Noticias/Pronun ciamiento\%20Magistrados.pdf (Consulta del 24/11/2017).

Acceso a la justicia (2015a). Así sería la preselección de magistrados si se respetara la ley. Recuperado de:

http://www.accesoalajusticia.org/noticias/detalle.php?notid=13119\#.WXZ BY1GQyUn (Consulta del 24/11/2017).

Acceso a la justicia (2015b). Asamblea saliente sin tiempo para nombrar magistrados. Recuperado de:

http://www.accesoalajusticia.org/noticias/detalle.php?notid=13119\#.WXZ BY1GQyUn (Consulta del 24/11/2017).

Amnistía Internacional (2015a) Uso de la fuerza. Directrices para la aplicación de los principios básicos sobre el empleo de la fuerza y de armas de fuego por los funcionarios encargado de hacer cumplir la ley. Amsterdam, Países Bajos. Recuperado de:

https://www.amnesty.nl/content/uploads/2017/01/ainl uso de la fuerza esp 0.pdf?x73272 (Consulta del 24/11/2017).

Amnistía Internacional (2015b). VENEZUELA: LOS ROSTROS DE LA IMPUNIDAD: A UN AÑO DE LAS PROTESTAS, LAS VICTIMAS AÚN ESPERAN JUSTICLA, AMR 53/1239/2015. Obtenido el 14 de enero de:

https://www.amnesty.org/es/documents/amr53/1239/2015/es/ Amnistía Internacional (1993), VENEZUELA: EL ECLIPSE DE LOS DERECHOS HUMANOS, AMR 53/07/93. Recuperado de: https://www.amnesty.org/download/Documents/188000/amr53007 1993es.pdf

Asamblea General de la ONU (17 de diciembre, 1979). Código de conducta para funcionarios encargados de hacer cumplir la ley. Recuperado de: http://www.ohchr.org/SP/ProfessionalInterest/Pages/LawEnforcem entOfficials.aspx

Asamblea General de la ONU (16 de diciembre, 1966). Pacto Universal de Derechos Civiles y Políticos, Recuperado de:

http://www.ohchr.org/SP/ProfessionalInterest/Pages/CCPR.aspx 
Asamblea General de la ONU (1948). Declaración Universal de los Derechos Humanos. París. Recuperado de http://www.un.org/es/universal-declaration-human-rights/index. $\underline{\mathrm{html}}$

Ávila, K. (2017b) "Las Operaciones de Liberación del Pueblo (OLP): entre las ausencias y los excesos del sistema penal en Venezuela". En Revista Crítica Penal y Poder. Recuperado de:

http://revistes.ub.edu/index.php/CriticaPenalPoder/article/view/16878

(Consulta del 24/11/2017).

Ávila, K. (2015) "Seguridad ciudadana y seguridad de la nacional. La lucha por el control de las manifestaciones y el orden público en Venezuela". En Libro Homenaje a la Academia de Ciencias Políticas y Sociales en el centenario de su fundación 1915-2015, págs. 504-511. Recuperado de: https://www.academia.edu/21594916/Seguridad Ciudadana y Segur idad Nacional La lucha por el control de las manifestaciones $y$ del orden $\mathrm{p} \% \mathrm{C} 3 \%$ BAblico en Venezuela

Comité Internacional de La Cruz Roja (2008). Violencia y uso de fuerza. Ginebra. Recuperado de: https://www.icrc.org/spa/assets/files/other/violencia-y-uso-de-1 a-fuerza (web).pdf

Consejo General de Policía (2012) 6. Respuestas en concierto. Manual de actuación de los cuerpos de policía para garantizar el orden público, la paz social y la convivencia ciudadana en reuniones públicas y manifestaciones. Baquía. Reglas mínimas de estandarización para los cuerpos policiales. Caracas.

Del Olmo, R. (1990). Segunda Ruptura Criminológica. Universidad Central de Venezuela, Facultad de Ciencias Jurídicas y Políticas, Instituto de Ciencias Penales, Caracas.

Hernández, T. (1989) Del mal necesario al bien indeseable: operativos policiales y delincuencia en Venezuela (1958-1986). Tesis de doctorado. Universidad Central de Venezuela, Caracas.

Ministerio Público (2017a), Informe Anual de Gestión 2016. Caracas. Recuperado de: http://www.mp.gob.ve/c/document library/get file?uuid=caa5a53d $=7 \mathrm{e} 70-4716-958 \mathrm{e}-0986 \mathrm{~b} 593 \mathrm{~b} 266$ \&groupId=10136 (Consulta del 24/11/2017).

Ministerio Público (2017b). Balance de víctimas fallecidas y lesionadas durante manifestaciones desde el 6 abril al 27 de julio de 2017. Caracas. 
Observatorio Electoral Venezolano (2017a). El OEV te presenta once preguntas y respuestas sobre las bases comiciales constituyentes. Recuperado de: http://www.oevenezolano.org/2017/05/23/lo-que-se-sabe-hasta =ahora-sobre-las-bases-comiciales-constituyentes/ (Consulta del 24/11/2017).

Observatorio Electoral Venezolano (2017b). El CNE elimina 14 auditorías y debilita el sistema electoral. Recuperado de: http://www.oevenezolano.org/2017/06/16/cne-elimina-14-audito rias-y-debilita-el-sistema-electoral/ (Consulta del 24/11/2017).

Observatorio Electoral Venezolano (2017c) Domingo 30: La elección de la ANC no es transparente. Recuperado de:

http://www.oevenezolano.org/2017/07/28/domingo-30-los-resul tados-seran-confiables/ (Consulta del 24/11/2017).

Observatorio Venezolano de Conflictividad Social (2017). Venezuela: 6.729 protestas y 163 fallecidos desde el 1 de abril de 2017. Recuperado de: https://www.observatoriodeconflictos.org.ve/tendencias-de-la-co nflictividad/venezuela-6-729-protestas-y-157-fallecidos-desde =el-1-de-abril-de-2017 (Consulta del 24/11/2017).

Oficina del Alto Comisionado de las Naciones Unidas para los Derechos Humanos (2017), Violaciones y abusos de los derechos bumanos en el contexto de las protestas en la República Bolivariana de Venezuela del 1 de abril al 31 de julio de 2017. Ginebra. Obtenido el 14 de enero de 2018, de: http://www.ohchr.org/Documents/Countries/VE/HCReportVenez uela 1April-31July2017 SP.pdf

Oficina del Alto Comisionado de las Naciones Unidas para los Derechos Humanos (1990). Principios básicos sobre el empleo de la fuerza y de armas de fuego por los funcionarios encargados de hacer cumplir la ley, [versión electrónica]. La Habana, Cuba. Obtenido el 24 de noviembre de 2017, de:

http://www.ohchr.org/SP/ProfessionalInterest/Pages/UseOfForceA ndFirearms.aspx

República Bolivariana de Venezuela (2014) Decreto con Rango Valor y Fuerza de Ley Orgánica de la Fuerza Armada Nacional Bolivariana. En Gaceta Oficial 6.156, Caracas.

República Bolivariana de Venezuela (2011) Normas sobre la actuación de los cuerpos de policía en sus diversos ámbitos político territoriales para garantizar el orden público, la paz social y la convivencia ciudadana en 
reuniones públicas y manifestaciones (NACPOP). En Gaceta Oficial $N^{o}$ 39.658, Caracas.

República Bolivariana de Venezuela (2009a). Ley del Estatuto de la Función Policial. En Gaceta Oficial No 5.940, Caracas.

República Bolivariana de Venezuela (2009b). Ley Orgánica del Servicio de Policía y del Cuerpo de Policía Nacional Bolivariana. En Gaceta Oficial $N^{o}$ 5.940, Caracas.

República Bolivariana de Venezuela (2001). Ley de Coordinación de Seguridad Ciudadana. En Gaceta Oficial No 37.318, Caracas.

República Bolivariana de Venezuela (2000) Constitución de la República Bolivariana de Venezuela. G.O.E. No 5.453 del 24 de marzo de 2000.

Tribunal Supremo de Justicia (2017a). Sentencia 155. Recuperado de: http://historico.tsj.gob.ve/decisiones/scon/marzo/197285-155-28 317-2017-17-0323.HTML (Consulta del 24/11/2017).

Tribunal Supremo de Justicia (2017b). Sentencia 156. Recuperado de: http://historico.tsj.gob.ve/decisiones/scon/marzo/197364-156-29 317-2017-17-0325.HTML (Consulta del 24/11/2017).

\section{Referencias hemerográficas y páginas web}

Agencia Venezolana de Noticias (7/1/2016) Juramentado Nelson Moreno como gobernador del estado Anzoátegui. Recuperado de: http://www.avn.info.ve/contenido/ist $\% \mathrm{C} 3 \%$ BAriz-notifica-consej o-legislativo-anzo $\% \mathrm{C} 3 \% \mathrm{~A} 1$ tegui-designaci $\% \mathrm{C} 3 \% \mathrm{~B} 3 \mathrm{n}$-como-vice presidente-ejecutivo (Consulta del 24/11/2017).

Alba Ciudad (9/8/2016) CNE: Referendo revocatorio se realizaría en 2017 si cumplen requisitos. Recuperado de: http://albaciudad.org/2016/08/cne-referendo-revocatorio-para-2 017/ (Consulta del 24/11/2017).

Analítica (14/6/2017) Rosal: "Designación de gobernador de Carabobo puede durar solo 30 días". Recuperado de: http://www.analitica.com/actualidad/actualidad_nacional/rosal—des ignacion-de-gobernador-de-carabobo-puede-durar-solo-30-d ias/ (Consulta del 24/11/2017).

Ávila, K. (26/07/2017a) ¿Cómo llegamos al 30 de julio? Los desafortunados eventos que nos trajeron basta acá. Contrapunto. Recuperado de http://contrapunto.com/noticia/como-llegamos-al-30-de-julio149918/ (Consulta del 27/11/2017). 
Ávila, K. (29/07/2017b) Balance de muertes violentas vinculadas con la conflictividad política. Contrapunto. Recuperado de: http://contrapunto.com/noticia/balance-de-muertes-violentas-vi nculadas-con-la-conflictividad-politica-150419/ (Consulta del 27/11/2017).

Ávila, K. (18/07/2017d) "Las pruebas de la verdad" Sobre la comiquita del polígrafo. Contrapunto. Recuperado de: http://contrapunto.com/noticia/las-pruebas-de-la-verdad-1482 68/ (Consulta del 24/11/2017).

Ávila, K. (29/06/2017e) El desmantelamiento del Ministerio Público. Contrapunto. Recuperado de:

http://contrapunto.com/noticia/el—desmantelamiento-del-ministerio-p ublico-144683/

Ávila, K. (01/06/2017f) Balance de hechos violentos: del 6 de abril al 25 de mayo. Contrapunto. Recuperado de:

http://contrapunto.com/noticia/balance-de-hechos-violentos-del =6-de-abril-al-25-de-mayo-139695/) (Consulta del 27/11/2017).

Ávila, K. (03/05/2017g) La constitución como pharmakos. Contrapunto. Recuperado de: http://contrapunto.com/noticia/la-constitucion-como-pharmakos $=134110 /$ (Consulta del 24/11/2017).

Ávila, K. (03/04/2017h) Peor el remedio. El supremo desastre. Contrapunto. Recuperado de: http://www.contrapunto.com/noticia/peor-el-remedio-el-supre mo-desastre-129445/(Consulta del 24/11/2017).

BBC (21/10/2016a). Venezuela: el CNE paraliza el referendo revocatorio a Nicolás Maduro. Recuperado de: http://www.bbc.com/mundo/noticias-america-latina-37723172 (Consulta del 24/11/2017).

BBC (18/10/2016b). El CNE aplaza por seis meses las elecciones regionales en Venezuela. Recuperado de:

http://www.bbc.com/mundo/noticias-america-latina-37699764 (Consulta del 24/11/2017).

Camacho, Y. (6/6/2017) Argenis Chávez será juramentado como gobernador de Barinas. El Nacional. Recuperado de: http://www.el-nacional.com/noticias/gobierno/argenis-chavez-se 
ra-juramentado-como-gobernador-barinas 186287 (Consulta del 24/11/2017).

Cano, María (2/9/2016) Arco Minero del Orinoco vulnera fuentes vitales y diversidad cultural en Venezuela. La Izquierda Diario. Recuperado de: http://www.laizquierdadiario.com.ve/Arco-Minero-del-Orinocovulnera-fuentes-vitales-y-diversidad-cultural-en-Venezuela

(Consulta del 24/11/2017).

Carcione, Carlos (17/08/2017) Entrevista a Keymer Ávila, profesor de la Universidad Central de Venezuela. «Tiene que determinarse la responsabilidad de todas estas muertes». Rebelión. Recuperado de: http://www.rebelion.org/noticia.php?id=230332 (Consulta del 24/11/2017).

Contrapunto (17/2/2017). Magistrados jubilados denuncian que fueron presionados para retirarse. Recuperado de

http://contrapunto.com/noticia/magistrados-jubilados-denuncian =que-fueron-presionados-para-retirarse-62173/ (Consulta del 24/11/2017).

Crespo, C. (09/01/2017) La Asamblea Nacional acató y desacató al TSJ en un mismo día. Crónica Uno. Recuperado de http://cronica.uno/asamblea-acato-desacato-tsj-mismo-dia/ (Consulta del 24/11/2017).

Diario de Lara La Prensa (28/07/2017). FISCAL $21^{\circ}$ INVESTIGARÁ ASESINATO DE JOSÉ PESTANO. Recuperado de: http://www.laprensalara.com.ve/?p=383536 (Consulta del $17 / 1 / 2018)$

El Carabobeño (27/07/2017): Fiscalía confirmó muerte de Leonardo González,por impacto de bala en la espalda. Recuperado de: https://www.el-carabobeno.com/fiscalia-confirmo-muerte-leonar do-gonzalez-impacto-bala-la-espalda/ (Consulta del 17/1/2018)

El Cooperante (30/07/2017). Privado de libertad funcionario de la PNB implicado en el asesinato de Rafael Ganache. Recuperado de:: https://elcooperante.com/privado-de-libertad-funcionario-de-la =pnb-implicado-en-el-asesinato-de-rafael-ganache/ (Consulta del 17/1/2018)

El Nacional (11/1/2018). Reportaron protesta en la carretera vieja Caracas-Los Teques. El Nacional. Recuperado de: http://www.el-nacional.com/noticias/protestas/reportaron-protest 
a-carretera-vieja-caracas-los-teques 218287 (Consulta del $14 / 1 / 2018)$

El Nacional (12/6/2017a) Ortega Díaz impugnó nombramiento de magistrados del TSJ. Recuperado de:

http://www.el-nacional.com/noticias/politica/ortega-diaz-impugno-no mbramiento-magistrados-del-tsj_187300 (Consulta del 24/11/2017).

El Nacional (6/4/2017b) Opositores podrán firmar para apoyar destitución de magistrados. Recuperado de:

http://www.el-nacional.com/noticias/oposicion/opositores-podran-fir mar-para-apoyar-destitucion-magistrados 89266 (Consulta del 24/11/2017).

El Nacional (6/4/2017c) Estudiantes protestan en la avenida intercomunal de Guarenas. Recuperado de:

http://www.el-nacional.com/noticias/protestas/estudiantes-protestan-a venida-intercomunal-guarenas 89279 (Consulta del 24/11/2017).

El Nacional (5/4/2017d) Los siete puntos de encuentro de la marcha opositora bacia la autopista. Recuperado de:

http://www.el-nacional.com/noticias/oposicion/los-siete-puntos-encu entro-marcha-opositora-hacia-autopista 89128 (Consulta del 24/11/2017).

El Nacional (5/4/2017e) GNB y manifestantes de la oposición se enfrentaron en la avenida Libertador. Recuperado de: http://www.el-nacional.com/noticias/protestas/gnb-manifestantes -oposicion-enfrentaron-avenida-libertador 88907 (Consulta del 24/11/2017).

El Nacional (2/8/2016) TSJ anula incorporación de diputados de Amazonas. Recuperado

de: http://www.el-nacional.com/noticias/politica/tsj-anula-incorpora cion-diputados-amazonas 22711 (Consulta del 24/11/2017).

El Nacional (31/12/2015). Designación de magistrados obvió fase de impugnación. Recuperado de:

http://www.el-nacional.com/noticias/politica/designacion-magistradosobvio-fase-impugnacion 43320 (Consulta del 24/11/2017).

El Universal (5/6/2017) Profesores constitucionalistas de la UCV rechazaron Constituyente. Recuperado de:

http://www.eluniversal.com/noticias/politica/profesores-constituci 
onalistas-ucv-rechazaron-constituyente 655807 (Consulta del 24/11/2017).

El Universal (19/10/2016a) CNE fijó elecciones de gobernadores para finales de primer semestre de 2017. Recuperado de:

http://www.eluniversal.com/noticias/politica/cne-fijo-elecciones-gober nadores-para-finales-primer-semestre-2017 623173 (Consulta del 24/11/2017).

El Universal (28/07/2016b) Diputados de Amazonas fueron reincorporados a la Asamblea Nacional. Recuperado de:

http://www.eluniversal.com/noticias/politica/diputados-amazonas-fuero n-reincorporados-asamblea-nacional 420916 (Consulta del 24/11/2017).

Efecto Cocuyo (15/1/2018) "El Uno", líder del "colectivo Tres Raíces", murió en operativo contra Óscar Pérez. Recuperado de:

http://efectococuyo.com/principales/el-uno-lider-del-colectivotres-raices-murio-en-operativo-contra-oscar-perez (Consulta del 16/1/2018)

Embajada de la República Bolivariana de Venezuela en Cuba (13/1/2016) Asamblea Nacional acata sentencia del TSJ y desincorpora a candidatos juramentados por Amazonas. Recuperado de: http://cuba.embajada.gob.ve/index.php?option=com content\&view =article\&id $=2429 \% 3$ Aasamblea - nacional-acata-sentencia-del-tsi $=\mathrm{y}-$ desincorpora-a-candidatos-juramentados-por-amazonas\&ca tid=3\%3Anoticias-de-venezuela-en-el-mundo\&Itemid=19\&lang Ees (Consulta del 24/11/2017).

Falak, M. (31/03/2017) Temible: la vulneración de la democracia en Venezuela eleva la crisis a la calle. Ámbito.com. Recuperado de: http://www.ambito.com/877790-temible-la-vulneracion-de-lademocracia-en-venezuela-lleva-la-crisis-a-la-calle (Consulta del $24 / 11 / 2017)$

Flores, J. (15/1/2018) Silencio del MP y Defensoría contribuyó a final violento en operativo contra Óscar Pérez. Efecto Cocuyo. Recuperado de: http://efectococuyo.com/principales/el-uno-lider-del-colectivotres-raices-murio-en-operativo-contra-oscar-perez (Consulta del 16/1/2018)

Hernández, J. (07/10/2017a) La designación de magistrados del TSJ por la AN. ¿Fraude Constitucional? Prodavinci. Recuperado de: 
http://prodavinci.com/blogs/puede-la-asamblea-nacional-design ar-magistrados-del-tsj-por-jose-ignacio-hernandez-g/

(Consulta del 24/11/2017).

Hernández, J. (20/06/2017b) Decisión del TSJ: el intento de remover a la Fiscal. Prodavinci. Recuperado de: http://prodavinci.com/blogs/decision-del-tsj-el-intento-de-re mover-a-la-fiscal-por-jose-ignacio-hernandez/ (Consulta del 24/11/2017).

Hernández, J. (30/03/2017c) Sentencia 156: el TSJ usurpa funciones de la Asamblea Nacional. Prodavinci. Recuperado de:

http://prodavinci.com/blogs/sentencia-156-el-tsj-usurpa-funciones-

de-la_asamblea-nacional-por-jose-ignacio-hernandez/?platfor $\underline{m}=$ hootsuite (Consulta del 24/11/2017).

Hernández, J. (28/03/2017d) ¿Qué dijo la Sala Constitucional sobre la AN y la Carta Democrática? Prodavinci. Recuperado de: http://prodavinci.com/blogs/que-dijo-la-sala-constitucional-sob re-la-an-y-la-carta-democratica-por-jose-ignacio-hernandez $\angle$ (Consulta del 24/11/2017).

Hernández, J. (09/01/2017e) Declarado el abandono del cargo: iy abora qué? Prodavinci. Recuperado de: http://prodavinci.com/blogs/declarado-el-abandono-del-cargoy-ahora-que-por-jose-ignacio-hernandez/) (Consulta del 24/11/2017).

Hernández, J. (07/01/2016) La AN juramentó a tres diputados de Amazonas: ¿Y ahora? Prodavinci. Recuperado de: http://prodavinci.com/blogs/la-an-juramento-a-tres-diputados =de-amazonas-y-que-viene-ahora-por-jose-ignacio-hernand ez-g/ (Consulta del 24/11/2017).

Hernández, J. (10/12/2015a) ¿Qué puede hacer la nueva AN si nombran a los magistrados antes de instalarse? Prodavinci. Recuperado de: http://prodavinci.com/blogs/que-puede-hacer-la-nueva-an-si =nombran-a-los-magistrados-antes-instalarse-por-jose-i-her nandez/ (Consulta del 24/11/2017).

Hernández, J. (23/12/2015b). 5 violaciones cometidas durante la designación de los magistrados del TSJ. Prodavinci. Recuperado de: http://prodavinci.com/blogs/5-violaciones-cometidas-durante-la =designacion-de-los-magistrados-del-tsj-por-jose-i-hernand ez/ (Consulta del 24/11/2017). 
Ladera, M. (30/4/2017) Salida de Venezuela de la OEA marca el inicio del fin de esta organización. Ministerio de Comunicación e Información. Recuperado de: http://minci.gob.ve/2017/04/salida-venezuela-la-oea-marca-ini cio-del-fin-esta-organizacion/ (Consulta del 24/11/2017).

La Patilla (12/1/2018) Más de 20 detenidos tras intento de saqueo a camión de pollos en Cojedes. Recuperado de:

https://www.lapatilla.com/site/2018/01/12/mas-de-20-detenidos -tras-intento-de-saqueo-a-camion-de-pollos-en-cojedes/ (Consulta del 16/1/2018)

León, I. (9/6/2017a) Exasesores de la Constituyente de 1999 alertan que está en juego la democracia participativa. Efecto Cocuyo. Recuperado de: http://efectococuyo.com/politica/exasesores-de-la-constituyente =de-1999-alertan-que-esta-en-juego-la-democracia-participa tiva (Consulta del 24/11/2017).

León, I. (31/1/2017b) Denuncian que nuevo gobernador de Sucre fue juramentado de forma irregular. Efecto Cocuyo. Recuperado de: http://efectococuyo.com/politica/denuncian-que-nuevo-gobernad or-de-sucre-fue-juramentado-de-forma-irregular (Consulta del 24/11/2017).

León, I. (31/10/2016) Dudas y respuestas sobre el "juicio político" y "abandono de cargo" del Presidente. Efecto Cocuyo. Recuperado de: http://efectococuyo.com/politica/dudas-y-respuestas-sobre-el-j uicio-politico- $\mathrm{y}-\mathrm{abandono}-\mathrm{de}-\mathrm{cargo}-\mathrm{del}-$ presidente (Consulta del 24/11/2017).

Manetto, F. (17/11/2017) La exfiscal de Venequela acusa en La Haya al régimen de Maduo de cometer más de 8.000 asesinatos. El País. Bogotá. Recuperado de:

https://elpais.com/internacional/2017/11/16/america/1510850769 180858.html (Consulta del 24/11/2017).

Ministerio Público (20/07/2017c). Ministerio Público imputará a tres hombres por muerte de sexagenaria en Catia. Recuperado de: http://www.mp.gob.ve/web/guest/33?p p id=62 INSTANCE 9Ey g\&p $\mathrm{p}$ lifecycle $=0 \& \mathrm{p} \mathrm{p}$ state $=$ maximized $\& \mathrm{p} \mathrm{p}$ mode $=$ view $\& \mathrm{p} p \mathrm{c}$ ol id=column-2\&p p col pos=1\&p p col count $=2 \& 62$ INSTA NCE 9Eyg struts action=/journal articles/view\& 62 INSTANCE 
9Eyg groupId=10136\& 62 INSTANCE 9Eyg articleId=17332204 \& 62 INSTANCE 9Eyg version=1.0 (Consulta del 31/7/2017).

Moreno, V. (10/1/2018a)_Un muerto y 59 detenidos tras dos días de saqueos en seis estados.

Efecto

Cocuyo.

http://efectococuyo.com/principales/un-muerto-y-59-detenidos

=tras-dos-dias-de-saqueos-en-seis-estados (Consulta del $16 / 1 / 2018)$.

Moreno, V. (16/1/2018b) Oscar Pérez: asesinado en un operativo militar y policial que él mismo transmitió. Efecto Cocuyo. Recuperado de: http://efectococuyo.com/principales/oscar-perez-asesinado-en-u n-operativo-militar-y-policial-que-el-mismo-transmitio

(Consulta del 16/1/2018).

Ortega, L. (31/3/2017a) Presentación del Informe Anual del Ministerio Público 2016. Recuperado de https://www.pscp.tv/w/1LyxBjNyqqzxN (Consulta del 5-8-2017). Extracto disponible en: https://www.youtube.com/watch?v=gQSFLOjSSIA

Ortega, L. (8/8/2017b). Al pueblo de \#Venezuela y la comunidad internacional \#8Ago: [publicación de Twitter]. Recuperado de: https://twitter.com/lortegadiaz/status/895062200204894208 (Consulta del 24/11/2017).

Otero, M. (26/12/2016) La anunciada tragedia del Arco Minero. El Nacional. Recuperado de:

http://www.el—nacional.com/noticias/editorial/anunciada—tragedia-del_arco-minero 72575 (Consulta del 24/11/2017).

Panorama (15/06/2017) Fiscal General solicitó nulidad de decretos presidenciales que convocan a la Constituyente. Recuperado de: http://www.panorama.com.ve/politicayeconomia/Fiscal-General-s olicito-nulidad-de-decretos-presidenciales-que-convocan-a-la -Constituyente-20170615-0045.html (Consulta del 24/11/2017).

Peñaloza, P. (9/1/2017) Asamblea de Venezuela aprueba la destitución de Maduro por "abandono del cargo". Univisión Noticias. Recuperado de: http://www.univision.com/noticias/crisis-en-venezuela/asambleade-venezuela-aprueba-la-destitucion-de-maduro-por-abandon o-del-cargo (Consulta del 24/11/2017).

Pineda, J. (4/4/2017) Sesión para destituir a magistrados se realizará el 5 de abril por represión del \#4A. Efecto Cocuyo. Recuperado de: http://efectococuyo.com/politica/sesion-para-destituir-a-magistr 
ados-se-realizara-el-5-de-abril-por-represion-del-4a (Consulta del 24/11/2017).

Programa Venezolano de Educación-Acción en Derechos Humanos (PROVEA) (11/1/2018). \#11Ene Con los 4 lamentables asesinatos ocurridos hoy en estado \#Merida en el marco de protestas suman 7 personas asesinadas en once días en circunstancias relacionadas a obtención de alimentos. Investigación y sanción a responsables [publicación de Twitter]. Recuperado de: https://twitter.com/ Provea/status/951631785468792834 (Consulta del 16/1/2018).

Reyes, L. (30/3/2017) Con sentencias 155 y 156, TSJ habilita al presidente Maduro a legislar y bloquean a la AN. Efecto Cocuyo. Recuperado: http://efectococuyo.com/politica/con-sentencias-155-y-156-tsj -habilita-al-presidente-maduro-a-legislar-y-bloquea-a-la-an (Consulta del 24/11/2017).

Telesur (04/08/2017a) Instalan en Venezuela Asamblea Nacional Constituyente. Recuperado de: https://www.telesurtv.net/news/Instalan-en-Venezuela-Asamblea =Nacional-Constituyente-20170804-0044.html (Consulta del 24/11/2017).

Telesur (09/01/2017b) ¿Por qué la AN no puede declarar el "abandono de cargo" de Nicolás Maduro? Recuperado de: http://www.telesurtv.net/news/Por-que-la-AN-no-puede-decl arar-el-abandono-de-cargo-de-Nicolas-Maduro-20170109-00 42.html (Consulta del 24/11/2017).

Terán, E. (22/4/2017) Venezuela desde adentro: siete claves para entender la crisis actual. Frontal 27. Recuperado de: http://frontal27.com/venezuela-desde-adentro-siete-claves-para -entender-la-crisis-actual/ (Consulta del 24/11/2017).

YVKE Radio Mundial (28/07/2017), Investigan muerte de oficial de la Policía de Mérida. Obtenido el 17 de enero, 2018: http://www.radiomundial.com.ve/article/investigan-muerte-de-ofi cial-de-la-polic $\% \mathrm{C} 3 \% \mathrm{ADa}-\mathrm{de}-\mathrm{m} \% \mathrm{C} 3 \% \mathrm{~A} 9$ rida $\quad$ (Consulta del 17/1/2018). 